Research Article

\title{
Comprehensive Benefit Evaluation of Cemented Paste Backfill in the Mining Industry
}

\author{
Yan Li iD \\ School of Business, Xi'an University of Finance and Economics, Xi'an 710100, China \\ Correspondence should be addressed to Yan Li; liyan@xaufe.edu.cn
}

Received 30 December 2020; Revised 16 February 2021; Accepted 1 March 2021; Published 11 March 2021

Academic Editor: Musa Adamu

Copyright (c) 2021 Yan Li. This is an open access article distributed under the Creative Commons Attribution License, which permits unrestricted use, distribution, and reproduction in any medium, provided the original work is properly cited.

\begin{abstract}
With the increasing scrutiny on tailings management and requirements of the ground subsidence control, both the academia and industry are highly advocating the utilization of cemented paste backfill (CPB) in the mining industry. Literature review has shown that there are some studies conducted to evaluate the ecological environment, economic development, and social impact of mining. However, a comprehensive study about the economic benefits, resource benefits, environmental benefits, and social benefits of CPB is still lacking. This study aims to present a comprehensive benefit index system for CPB from four aspects, i.e., economy, resource, environment, and society. Questionnaires from experts and the mining industry using CPB technology were collected, and structural equation modeling (SEM) was used for data analysis. The relationships between economy, resource, environment, and society were analyzed. The results show that resource benefits have the greatest impact on the comprehensive benefit of $\mathrm{CPB}$ in the mining industry, followed by environmental, economic, and social benefits. According to relevance ranking, resource benefits are positively correlated with social, environmental, and economic benefits, whereas environmental, resource, and social benefits have correlation with economic benefits in turn. Therefore, resource, environmental, economic, and social benefits in order directly affect the comprehensive benefit of $\mathrm{CPB}$ on the basis of the influencing degree. Moreover, resource, environmental, and social benefits indirectly affect the comprehensive benefit of CPB. The research findings of this study would help the mining industry popularize the $\mathrm{CPB}$ technology and promote the sustainability and cleaner production of the mining industry.
\end{abstract}

\section{Introduction}

Cemented paste backfill (CPB) was first used at the Bad Grund Mine in Germany in the 1970s. CPB mixed the mine tailings (70-85 wt\%) with hydraulic binders (3-7 wt\%) and water to backfill into the underground voids [1]. Gradually, $\mathrm{CPB}$ has been successfully implemented in the Australian and Canadian mining industry as an innovative technique $[2,3]$. In recent years, $\mathrm{CPB}$ received a broad attention due to minimizing geological disaster [4]. However, the cost of cemented material is relatively high [5], which reduced the enthusiasm of some mining industries to adopt CPB method in China.

Three main backfill methods have emerged, i.e., rock fill, hydraulic fill, and paste fill [6]. Rock fill refers to solid waste produced in the process of underground mining, which is directly broken underground and transported to the working face for direct fill. Rock fill has the characteristics of being a simple process and relatively low investment cost, and the backfill cost is about $50 \mathrm{RMB} /$ ton in China [7]. The technology is suitable for mines with relatively low requirement of surface subsidence control [8]. Hydraulic fill applies less solid material and more water content; thus, it is appropriate for mines lacking solid filling materials and requiring low surface subsidence control. Paste fill is to process solid waste into slurry filling material on the ground and transport it to the underground working face by filling pipe. It is applicable to a wide range, especially to the mines with dense population and buildings and high requirement of subsidence control [9]. The cement was used as a cemented material in the process of paste fill, which was referred to as CPB [10]. Notably, cement expenditure accounts for approximately $75 \%$ of the cost of $\mathrm{CPB}$, which can take up $20 \%$ of the total mining cost [11]. The backfill cost is about 100 150 RMB/ton in China [9]. However, there are still 
some significant advantages of $\mathrm{CPB}$ : (i) $\mathrm{CPB}$ realizes the recycling of the mine tailing that is detrimental to the environment if a vast amount of tailing is piled up on the ground. The study shows that $60 \% \sim 75 \%$ of the tailings are used for rational utilization of resources [12]; (ii) $\mathrm{CPB}$ minimizes the risk of ground surface subsidence and protects the ecological environment around the mining area and the safety of aboveground buildings [13]; (iii) $\mathrm{CPB}$ enhances the resource recovery rate and decreases the rehabilitation cost [14]. In addition, the research on reduction of the cost of $\mathrm{CPB}$ is being conducted, focusing mainly on optimization of $\mathrm{CPB}$ mix parameters and exploring new cementitious materials instead of cement $[15,16]$.

Currently, the existing study focuses on the mining benefits. Kesimal et al. argued that $\mathrm{CPB}$ with tailings as filling material can bring potential environmental benefits, and the environmental benefits are analyzed in the northeastern part of Turkey [17]. Si et al. established three environmental indexes for economic benefits, environmental conditions, and resource protection and used AHP to analyze and evaluate the environmental sustainability of the coal industries [18]. Song et al. used the Data Envelopment Analysis (DEA) method to comprehensively assess the operational efficiency and environmental efficiency of Chinese coal industries [19]. Shang et al. combined the Delphi method, the AHP, and the fuzzy comprehensive evaluation method to establish a set of evaluation index systems involving phosphorus mining [20].

Although some scholars have considered the ecological environment, economic development, and social effect of the mining industry, few scholars have conducted in-depth study on comprehensive benefits of CPB. Moreover, there is no reasonable index system constructed for comprehensive benefit in accordance with the characteristics and advantages of CPB. In addition, the methods of benefit evaluation mainly include AHP, DEA, and fuzzy, whereas structural equation modeling (SEM) method has not been applied to the evaluation of backfill benefit. Based on what is mentioned above, this paper establishes a comprehensive benefit index system for CPB from four aspects, i.e., economy, resource, environment, and society, uses SEM to investigate its main influencing pathway, and evaluates the comprehensive benefit of CPB. SEM can systematically analyze relationships between the observed variables and latent variables, the relationship between endogenous latent variables and exogenous latent variables. SEM has been widely applied in some fields including psychology, marketing, banking, and environmental sciences. Therefore, it is significant to explore efficient factors leading to comprehensive benefit of $\mathrm{CPB}$ and to analyze direct or indirect relationships between the factors using SEM. The paper intends to give an integrated perspective for the mining industries, especially Chinese mining industries to promote positive application of $\mathrm{CPB}$ technology.

\section{Conceptual Framework and Hypothesis}

\subsection{Literature Review}

2.1.1. SEM. SEM can be applied to reveal the relationship between the observed variables, latent variables, and error variables involved in a model, and the two statistical methods of path analysis and factor analysis are integrated to explore the direct effect, indirect effect, or total effect of the independent variable on the dependent variable [21].

$$
\begin{aligned}
& X=\Lambda_{X} \xi+\delta, \\
& Y=\Lambda_{Y} \eta+\varepsilon, \\
& \eta=B \eta+\Gamma \xi+\zeta .
\end{aligned}
$$

SEM consists of two measured models and a structural model. Equation (1) represents the measured model of the exogenous variable. $\Lambda_{X}$ is the factor loading of the variable $X$, $\xi$ is the exogenous latent variable, and $\delta$ is the measurement error of the exogenous variable. Equation (2) indicates the measurement model of the endogenous variable. $\Lambda_{Y}$ is the factor loading of the variable $Y, \eta$ is the endogenous latent variable, and $\varepsilon$ is the measurement error of the endogenous variable in the equations; equation (3) states the structural model of the causal relationship between the endogenous latent variable and the exogenous latent variable. $B$ is the relationship matrix between the endogenous latent variable $\eta, \Gamma$ denotes the relationship matrix of the exogenous latent variable $\xi$ on the endogenous latent variable $\eta$, and $\zeta$ shows the part of the equation that cannot be explained.

\subsubsection{Comprehensive Benefit Evaluation}

(1) Economic Benefits Evaluation. Jasch pointed out that increased environmental performance may bring potential economic benefits, while traditional accounting practices cannot provide enough information for decision analysis [22]. In order to sufficiently indicate the utilization of resources and the protection of the environment by $\mathrm{CPB}$, it is necessary to set the index of incremental profit per unit, which is obtained by subtracting the unit incremental income and unit backfill cost. The costs of CPB mainly include backfill material fees, depreciation of backfill equipment, backfill electricity charge, labor expenditure, and the equipment maintenance cost in the late stage of backfill system. The incremental income induced by $\mathrm{CPB}$ has not still been shown in the accounting statements, and the incremental income saves a lot of costs for the mining industry through the utilization of solid waste and the protection of the ecological environment. For example, the disposal expenses of solid waste include gangue and fly ash, relocation costs, land acquisition and resettlement cost, land reclamation expense, expenditure for soil erosion compensation, expenditures for compensation of water and soil pollution, compensation expenditure of land subsidence, and compensation of atmosphere pollution [23]. According to the investigation, the direct economic losses caused by coal mining in Shanxi Province and the environmental treatment costs incurred therefrom exceed $100 \mathrm{RMB} /$ ton. The disposal cost of gangue in some areas such as Shanxi province reaches 25-50 RMB/ton [7]. In addition, backfill technology has received strong support from China's tax policy, and the resource tax will be reduced by $50 \%$ for the mineral 
resources extracted by backfill mining [24]. Moreover, the environmental protection tax law implemented in 2018 stipulates that the surface-disposal tailings are levied $15 \mathrm{RMB} /$ ton, and the fly ash discharged is levied $25 \mathrm{RMB} /$ ton [25]. So, taxes and fees reduced by the government owing to using CPB technology should be included in incremental income. The payback period and net present value are commonly used indexes in the evaluation of economic effect of a project, of which the net present value calculates the economic return of a project by discounting the cash flow [26]. Therefore, considering the money saved by $\mathrm{CPB}$ technology, the mining industries might find out more net present value and a shorter payback period than calculation by accounting statements when analyzing the economic effect.

(2) Resource Benefits Evaluation. The amount of gangue accounts for about $20 \%$ of coal production. A safe and environmentally friendly way to dispose of mining tailing such as the gangue is backfilling into the underground goaf. Simultaneously, the ore recovery rate increases [27]. Therefore, the ore recovery rate index and backfill utilization rate of gangue index reveal resource benefits of $\mathrm{CPB}$. The utilization rate of other resource refers to the utilization of fly ash, the utilization of waste heat, and the reuse of underground goaf. Deep mining of backfill to extract heat is of great significance for energy utilization [28]. At present, one of the research directions is to expand the backfill function for enhancing the incidental value of mine backfill [29].

(3) Environmental Benefits Evaluation. Li et al. collected raw coal production data from 1997 to 2010 in China, used a multiple linear regression model to observe the relationship between coal development and economic growth, and calculated environmental damage costs, which accounted for about $0.16 \%$ of GDP and accounted for $2.7 \%$ of average price of coal in 2010 [30]. CPB method enables obvious alleviation of surface subsidence and reduction of the occurrence of geological disaster [31]. When solid waste such as the gangue is stacked on the ground, in which the toxic elements will be released into the atmosphere and soil, as a result, surrounding ecosystems suffer destruction [32]. Moreover, gangue continuously accumulates heat, and spontaneous combustion of gangue occurs when the gangue is oxidized [33].

(4) Social Benefits Evaluation. Solid waste such as gangue accumulates and releases a lot of harmful gases such as $\mathrm{SO}_{2}, \mathrm{NO}_{x}$, and $\mathrm{CO}$ into the atmosphere, which influences the health of surrounding residents [12]. The application of CPB technology enables avoidance of the consequences of ground collapse; thus, the ground buildings on the goaf remain in stable condition [34]. Furthermore, CPB greatly reduces the difficulty of land reclamation and improves land reclamation rate [35].

2.2. Hypothesis. According to what is mentioned above, $\mathrm{CPB}$ has a beneficial impact on the environment, society, and economy through the recycling of solid waste. In addition, $\mathrm{CPB}$ technology enables minimization of ecological destruction, which saves environmental control cost for the mining industries. It means that protecting the ecological environment can bring profits to the industries. Therefore, some direct relationships between economic, resource, environmental, and social benefits might be proposed as follows:

$\mathrm{H1}$ : There is a significant positive correlation between resource benefits and economic benefits

$\mathrm{H} 2$ : There is a significant positive correlation between resource benefits and environmental benefits

H3: There is a significant positive correlation between resource benefits and social benefits

H4: There is a significant positive correlation between environmental benefits and economic benefits

H5: There is a significant positive correlation between social benefits and economic benefits

\section{Methodology}

Flow chart of SEM is shown in Figure 1. The first step is model specification, in which the comprehensive benefit evaluation index system for CPB is constructed, and variables are set. In the second step, in order to collect data, questionnaires are designed and distributed. In the third step, second-order confirmatory factor analysis model is established, and it is required to modify the model if the fit index value is not ideal. In the fourth step, causal analysis model among factors is formed. Similarly, the model needs to be modified until the optimal fitting effect. Finally, the results of the models are analyzed and explained.

3.1. Model Specification. Based on the economic, environmental, and social goals in the construction of green mines, this paper takes the resource utilization advantages of the mine backfill into account. A four-dimensional evaluation index system of economic-resource-environment-social benefits for the comprehensive benefit of CPB is constructed, as shown in Table 1 . To explore comprehensive benefit of $\mathrm{CPB}$ using SEM, it is indispensable to set latent variables and observed variables.

3.1.1. Latent Variables. There are 21 latent variables, including 4 endogenous latent variables, namely, "economic benefits," "resource benefits," "environmental benefits," and "social benefits," which are also called first-order factor constructs. There are 17 exogenous latent variables, including 16 error variables and a second-order factor construct, which is a comprehensive benefit of $\mathrm{CPB}$.

3.1.2. Observed Variables. It is intended to set 12 observed variables, in which three observed variables used to present latent variable "economic benefits" comprise "incremental profit per unit," "payback period," and "net present value." Three observed variables used to show latent variable "resource benefits" involve "ore recovery rate," "backfill utilization rate of gangue," and "utilization rate of other 


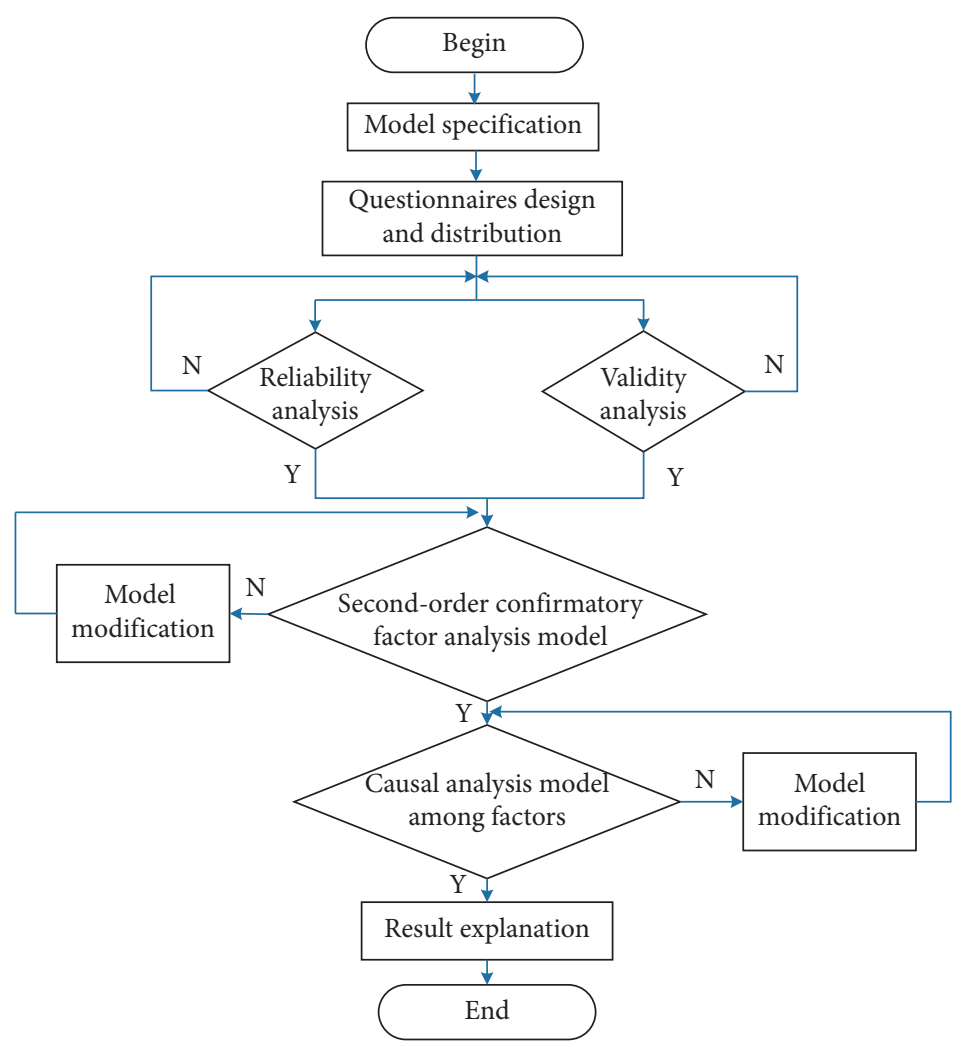

Figure 1: Flow chart of SEM.

TABLE 1: Comprehensive benefit evaluation index of CPB.

\begin{tabular}{|c|c|c|c|c|}
\hline Evaluation object & Latent variables & Observed variables & $\begin{array}{l}\text { Variable } \\
\text { symbol }\end{array}$ & References \\
\hline \multirow{12}{*}{$\begin{array}{l}\text { Comprehensive benefit of } \\
\text { CPB }\end{array}$} & \multirow{3}{*}{ Economic benefits } & Incremental profit per unit & B11 & Žižlavsk [26] \\
\hline & & Payback period & $\mathrm{B} 12$ & Qian et al. [23] \\
\hline & & Net present value & B13 & \\
\hline & \multirow{3}{*}{ Resource benefits } & Ore recovery rate & $\mathrm{B} 21$ & Tang and Wang [27] \\
\hline & & Backfill utilization rate of gangue & $\mathrm{B} 22$ & Agrawal et al. [28] \\
\hline & & Utilization rate of other resource & $\mathrm{B} 23$ & Liu et al. [25] \\
\hline & \multirow{3}{*}{$\begin{array}{l}\text { Environmental } \\
\text { benefits }\end{array}$} & Surface subsidence degree & B31 & Tariq and Yanful [31] \\
\hline & & Pollution amount of gangue & $\mathrm{B} 32$ & Cihangir et al. [32] \\
\hline & & $\begin{array}{c}\text { Spontaneous combustion pollution amount } \\
\text { of gangue }\end{array}$ & B33 & $\begin{array}{l}\text { Stracher and Taylor } \\
\text { [33] }\end{array}$ \\
\hline & \multirow{3}{*}{ Social benefits } & Prevalence rate of mine residents & B41 & $\mathrm{Li}$ and Wang [12] \\
\hline & & Land reclamation rate & B42 & Yang et al. [34] \\
\hline & & Housing integrity & B43 & Yilmaz et al. [35] \\
\hline
\end{tabular}

resource." Three observed variables used to express latent variables "environmental benefits" consist of "surface subsidence degree," "pollution amount of gangue," and "spontaneous combustion pollution amount of gangue." Three observed variables of the latent variable "social benefits" include "prevalence rate of mine residents," "land reclamation rate," and "housing integrity."

3.2. Data Collection. The questionnaire includes two parts. The basic information of participants is the first part. Since only some mining industries have adopted CPB technology in China, the study about the extension of the backfill function and corresponding benefits remains in the period of theoretical exploration. Therefore, the questionnaire considers part of the respondents who come from the mining industries in China, and part of the respondents invite the college teachers specialized in the mining engineering in China. Respondents were invited to answer the items of the questionnaires by e-mail. The questionnaires were emailed to the respondents of the mining industries, who held backfill technique and had the title of engineer. As shown in Table 2, the industries participating in the questionnaire are mainly located in eastern and northern China, such as Shandong and Shanxi provinces, which approximately account for $74 \%$ of the total industries. In addition, 
TABLE 2: Basic information of participants.

\begin{tabular}{|c|c|c|c|}
\hline Category & Item & Frequency & Percentage (\%) \\
\hline \multirow{6}{*}{ Participating industries (mining sites) } & East China & 22 & 44 \\
\hline & North China & 15 & 30 \\
\hline & Southwest region & 5 & 10 \\
\hline & Central China & 4 & 8 \\
\hline & Northwest region & 3 & 6 \\
\hline & Northeast region & 1 & 2 \\
\hline \multirow{3}{*}{ Expert title (universities \& research institutions) } & Lecturer & 17 & 21.25 \\
\hline & Associate professor & 29 & 36.25 \\
\hline & Professor & 34 & 42.50 \\
\hline
\end{tabular}

$78.75 \%$ of the experts who participated in the questionnaire had the title of associate professor or above. The second part of the questionnaire is the questions, and one observed variable corresponds to a question, a total of 12 items. The Likert seven-point scale was applied to set the question options, from 7 to 1 , corresponding from completely consistent to completely inconsistent. A total of 135 questionnaires were sent out, and there were the effective questionnaires received from fifty mining industries and eighty expert teachers, with an effective rate of $96.3 \%$.

3.3. Reliability Analysis. Reliability presents the stability or reliability of the questionnaire. Generally, a reliability coefficient greater than 0.7 indicates that the questionnaire is credible and acceptable [36]; if it is below 0.7, the results of this scale are less trustworthy. The reliability of the questionnaire data was analyzed by SPSS 23.0 software, and the reliability was tested by Cronbach's Alpha coefficient. Cronbach's Alpha values for each of the latent variables are shown in Table 3. The results showed that Cronbach's Alpha coefficient of each latent variable was greater than 0.7 , and the total Cronbach's Alpha coefficient was 0.858 , which was also greater than 0.7 ; thus, the questionnaire was highly reliable.

3.4. Validity Analysis. In addition to the reliability analysis of the data of the questionnaire, the validity of the measurement needs to be tested, which proves that the questionnaire enables us to measure variables more accurately. The factor loading reveals the correlation coefficient between the variable and the common factor. The larger the factor loading is, the closer the variable is to the common factor. A factor loading greater than 0.6 indicates acceptable validity. AVE is the average variance extraction. If $A V E>0.5$, it shows that the latent variable obtains a good convergence validity [37]. As shown in Table 4, the factor loadings are greater than 0.6, and AVE is greater than 0.5. This means that the scale has good convergence validity.

3.5. Second-Order Confirmatory Factor Analysis Model. The second-order confirmatory factor analysis model was constructed using AMOS22.0 software, as shown in Figure 2. Firstly, the first-order factors construct "economic benefits," "resource benefits," "environmental benefits," and "social benefits" as endogenous latent variables, which
TABLe 3: Reliability test value.

\begin{tabular}{lcc}
\hline Latent variable & Observed variable & Cronbach's alpha \\
\hline Economic benefits & 3 & 0.754 \\
Resource benefits & 3 & 0.859 \\
Environmental benefits & 3 & 0.933 \\
Social benefits & 3 & 0.909 \\
Overall & 12 & 0.858 \\
\hline
\end{tabular}

are expressed by their observed variables. On this basis, four first-order factor constructs measure the second-order factor construct, which reveals that the first-order factor constructs are affected by the second-order exogenous latent variables.

3.6. Causal Analysis Model among Factors. In order to study the mutual influence relationship between "economic benefits," "environmental benefits," "resource benefits," and "social benefits" that affect the comprehensive benefit of $\mathrm{CPB}$, causal analysis model among factors is built by using AMOS22.0 software, as shown in Figure 3.

\section{Results and Discussion}

\subsection{Results}

4.1.1. Second-Order Confirmatory Factor Analysis. The data was brought into the second-order confirmatory factor analysis model, and the model was successfully identified. The running result parameters are shown in Table 5. The absolute fitting index $(\mathrm{CMIN} / \mathrm{DF}=1.28, \mathrm{GFI}=0.93$, RMSEA $=0.047)$ and the relative fitting index $(\mathrm{NFI}=0.91$, $\mathrm{TLI}=0.93, \mathrm{CFI}=0.95)$ are all within the ideal range [38], presenting that the comprehensive benefit evaluation model of the mine CPB hypothesis is tenable. It shows that the evaluation of the comprehensive benefit of $\mathrm{CPB}$ is reasonable from the four aspects of economic, resource, environmental, and social benefits.

4.1.2. Causal Analysis Model among Factors. The values of the observed variables of economic benefits, resource benefits, environmental benefits, and social benefits are averaged, and the data is brought into the causality analysis model between factors. The model is successfully identified. The running result parameters are shown in Table 6: CMIN/ 
TABLE 4: Results of convergence validity.

\begin{tabular}{|c|c|c|}
\hline Observed variable & Factor loading & AVE \\
\hline Incremental profit per unit & 0.682 & \multirow{3}{*}{0.562} \\
\hline Payback period & 0.804 & \\
\hline Net present value & 0.758 & \\
\hline Ore recovery rate & 0.814 & \multirow{3}{*}{0.518} \\
\hline Backfill utilization rate of gangue & 0.773 & \\
\hline Utilization rate of other resource & 0.592 & \\
\hline Surface subsidence degree & 0.654 & \multirow{3}{*}{0.547} \\
\hline Pollution amount of gangue & 0.757 & \\
\hline Spontaneous combustion pollution amount of gangue & 0.800 & \\
\hline Prevalence rate of mine residents & 0.646 & \multirow{3}{*}{0.601} \\
\hline Land reclamation rate & 0.909 & \\
\hline Housing integrity & 0.824 & \\
\hline
\end{tabular}

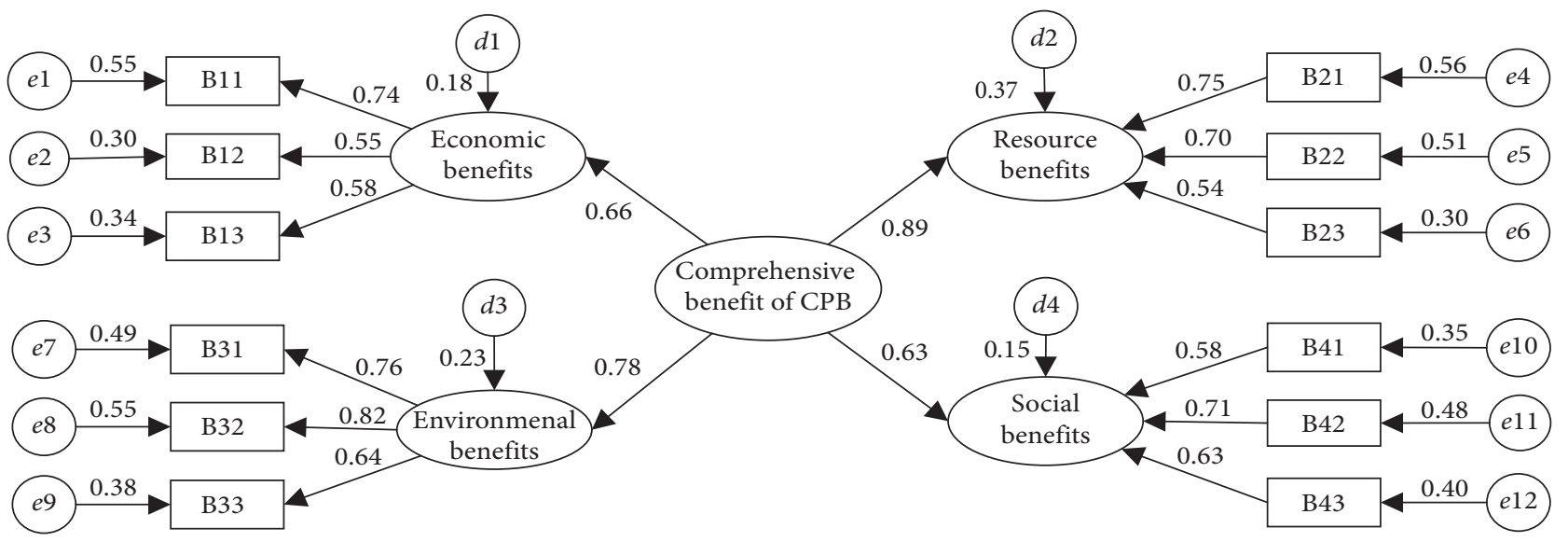

FIGURE 2: Second-order confirmatory factor analysis model.

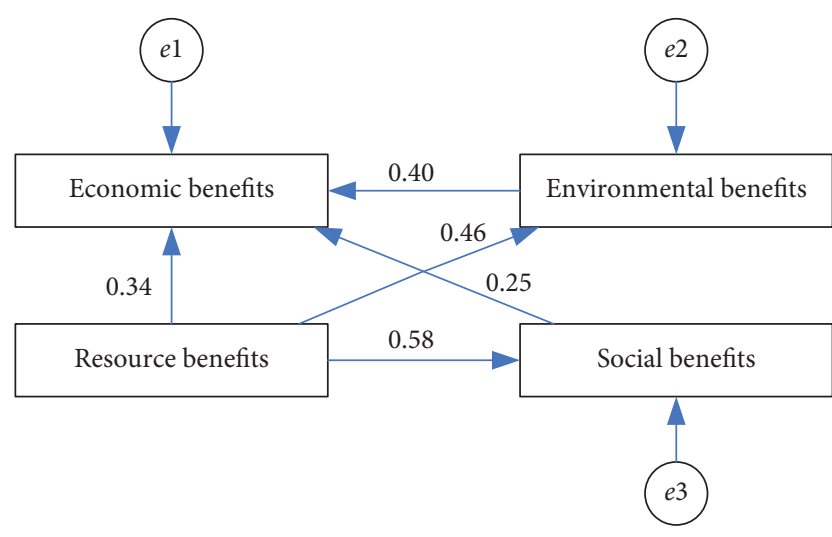

FIgURE 3: Causal relationship model between benefits.

$\mathrm{DF}=1.82, \quad \mathrm{GFI}=0.917, \quad \mathrm{RMSEA}=0.078, \quad \mathrm{NFI}=0.906$, $\mathrm{TLI}=0.924, \mathrm{CFI}=0.913$, indicating that the causality model between benefits has a good fit [39].

The maximum likelihood method is used to estimate the value of each path coefficient. As shown in Table 7, the $p$ values of the five path coefficients all reached a significant level of 0.05 , and the standardized regression coefficient $\beta$ is greater than 0 . The hypothetical relationship between the four benefits is established, and there is a correlation between resource benefits and social benefits, between resource benefits and environmental benefits, and between resources benefits and economic benefits. Besides, there is a correlation between environmental benefits and economic benefits, between resource benefits and economic benefits, and between social benefits and economic benefits.

\subsection{Discussion}

4.2.1. Effect of Resource Benefits. Resource benefits involve resource utilization of the solid waste. As shown in Figure 3, the comprehensive benefit of CPB is explained by the four benefits, among which the degree of interpretation of resource benefits is 0.89 ; thus, resource benefits have the greatest impact on the comprehensive benefits. From the resource benefits perspective, the resource benefits propose and explain ore recovery rate, backfill utilization rate of gangue, and utilization rate of other resource. The standard path coefficients are, respectively, 0.75 , 0.70 , and 0.54 , which indicate that $\mathrm{CPB}$ can greatly improve the ore recovery rate and simultaneously play an important role in the recycling of solid waste such as coal gangue. Finally, CPB also enables us to explore the utilization of other resources, such as the reuse of underground fill space and the utilization of mine waste heat, which will be a comprehensive utilization trend of $\mathrm{CPB}$ in the future. 
TABLE 5: Fit statistics of second-order confirmatory factor analysis model.

\begin{tabular}{lcc}
\hline Fit index & Index value & Ideal range \\
\hline CMIN/DF & 1.28 & $1 \sim 3$ \\
GFI & 0.93 & $>0.90$ \\
RMSEA & 0.047 & $<0.08$ \\
NFI & 0.91 & $>0.90$ \\
TLI & 0.93 & $>0.90$ \\
CFI & 0.95 & $>0.90$ \\
\hline
\end{tabular}

TABLe 6: Fit statistics of causal analysis model between factors.

\begin{tabular}{lcc}
\hline Fit index & Index value & Ideal range \\
\hline CMIN/DF & 1.82 & $1 \sim 3$ \\
GFI & 0.917 & $>0.90$ \\
RMSEA & 0.078 & $<0.08$ \\
NFI & 0.906 & $>0.90$ \\
TLI & 0.924 & $>0.90$ \\
CFI & 0.913 & $>0.90$ \\
\hline
\end{tabular}

TABle 7: Path coefficients and their significant values.

\begin{tabular}{lcc}
\hline Paths & Significant probability $(p)$ & Standardized regression weights $(\beta)$ \\
\hline Economic benefits $\leftarrow$ resource benefits & $* * *$ & 0.339 \\
Environmental benefits $\leftarrow$ resource benefits & $* * *$ & 0.461 \\
Social benefits $\leftarrow$ resource benefits & 0.039 & 0.579 \\
Economic benefits $\leftarrow$ environmental benefits & $* * *$ & 0.402 \\
Economics benefits $\leftarrow$ social benefits & 0.004 & 0.249
\end{tabular}

$* * *$ Significant at $p<0.001$ level.

4.2.2. Effect of Environmental Benefits. The environmental benefits pay close attention to the environmental advantages of $\mathrm{CPB}$. As shown in Figure 3, the comprehensive benefit of $\mathrm{CPB}$ has the degree of interpretation of environmental benefits of 0.78 , which shows that the impact of $\mathrm{CPB}$ on environmental benefits is second only to resource benefits. From the environmental benefits perspective, the environmental benefits explain surface subsidence degree, pollution amount of gangue, and spontaneous combustion pollution amount of gangue. The standard path coefficients are, respectively, $0.76,0.82$, and 0.64 , which reveal that $\mathrm{CPB}$ has significant influence in terms of environmental protection by means of recycling of the gangue. It is followed closely that $\mathrm{CPB}$ can efficiently minimize ground subsidence. Finally, CPB enables us to alleviate spontaneous combustion of gangue and reduce the atmosphere contamination.

4.2.3. Effect of Economic Benefits. Economic benefits investigate the comparison of investment cost and fill income of CPB. As shown in Figure 3, the comprehensive benefit of $\mathrm{CPB}$ has the degree of interpretation of economic benefits of 0.66 , which finds that CPB has a great impact on economic benefits, but the impact is less than resource benefits and environmental benefits. From the economic benefit perspective, the economic benefits explain incremental profit per unit, payback period, and net present value, in which standard path coefficients are, respectively, 0.74, 0.55, and 0.58 . This variable, incremental profit per unit, better exposes the economic benefits of $\mathrm{CPB}$. It is crucial that incremental income is concerned when the payback period and the net present value are calculated. The cost saving for the mining industries because of some factors including resource utilization and environmental protection should be fully considered, while the economic benefits of CPB are analyzed.

4.2.4. Effect of Social Benefits. The social benefits of CPB technology are beneficial for the mining industries to fulfil their social responsibilities. As shown in Figure 3, the comprehensive benefit of $\mathrm{CPB}$ has the degree of interpretation of social benefits of 0.63 , which is slightly lower than that of the economic benefits. It is concluded that there is less impact of $\mathrm{CPB}$ on social benefits compared with resources, environmental, and economic benefits. From the social benefit perspective, the social benefits explain prevalence rate of mine residents, land reclamation rate, and the housing integrity, and the standard path coefficients are, respectively, $0.58,0.71$, and 0.63 , indicating that the $\mathrm{CPB}$ has significant improvement on the land recovery and recycling, followed by the housing integrity, which shows that $\mathrm{CPB}$ technology did little damage to the ground buildings. Finally, CPB helps maintain the health of the mining residents.

4.2.5. Interaction of Four Benefits. It can be seen from Figure 3 that the impact of resource benefits on social, environmental, and economic benefits is $0.58,0.46$, and 0.34 , which indicate that resource benefits primarily affect social benefits, then environmental benefits, and finally economic 
benefits. In Table 5 , there is a significant $(p<0.05)$ positive $(\beta=0.579)$ correlation between resource benefits and social benefits, and a significant $(p<0.05)$ positive $(\beta=0.461)$ correlation between resource benefits and environmental benefits. Moreover, resource benefits and economic benefits had significantly $(p<0.05)$ positive $(\beta=0.393)$ correlation. Therefore, resource benefits indirectly affect the comprehensive benefit due to direct relevance to social, environmental, and economic benefits.

At the same time, the impacts of environmental, resource, and social benefits on economic benefits are 0.40 , 0.34 , and 0.25 , which reveal that environmental benefits have the greatest impact on economic benefits, and the impact of resource benefits on economic benefits is of secondary importance, and the influence of social benefits on economic benefits is of relatively little importance. The above-mentioned resource benefits are related to economic benefits. Additionally, there is a significantly $(p<0.05)$ positive $(\beta=0.402)$ correlation between environmental benefits and economic benefits, and there is a relatively less significant $(p<0.05)$ positive $(\beta=0.249)$ correlation between social benefits and economic benefits, shown in Table 5, which presents that environmental benefits, resource benefits, and social benefits are directly associated with economic benefits. As a result, environmental benefits, resource benefits, and social benefits indirectly affect the comprehensive benefit by a way of directly influencing economic benefits.

\section{Conclusions}

(1) This paper applies literature review method and questionnaire to construct comprehensive benefit evaluation index for CPB from four aspects, i.e., economic benefits, resource benefits, environmental benefits, and social benefits. There are 12 observed variables to support them.

(2) SEM is used to evaluate the comprehensive benefit of CPB. A second-order confirmatory factor analysis model and a causal relationship model among benefits are constructed. The data fits the model well. The results show that, from the first-order confirmatory factor analysis, the standard path coefficient of ore recovery rate is 0.75 , which is the most effective factor to explain resource benefits; the standard path coefficient of pollution amount of gangue is 0.82 , which is the most effective factor to indicate environmental benefits. The standard path coefficient of Incremental profit per unit is 0.74 , which is the most effective factor to reveal economic benefit; the standard path coefficient of land reclamation rate is 0.71 , which is the most effective factor to explore social benefits.

(3) In the four first-order factor constructs, the standard path coefficient of resource benefits to the comprehensive benefit of $\mathrm{CPB}$ is 0.89 , which is the most important influencing factor. In addition, the second influencing factor is environmental benefits, the third is economic benefits, and the fourth is social benefits. Simultaneously, resource benefits are associated with social, environmental, and economic benefits; thus, resource benefits directly and indirectly reach the impact on comprehensive benefit. Moreover, environmental benefits, resource benefits, and social benefits connect with economic benefits. Therefore, the four benefits including resource, environmental, social, and economic benefits are related with the comprehensive benefit. Besides, environmental, resource, and social benefits can indirectly influence the comprehensive benefit.

\section{Data Availability}

All the data are valid and included in the manuscript.

\section{Conflicts of Interest}

The authors declare that they have no conflicts of interest.

\section{Acknowledgments}

This research was supported by the National Natural Science Foundation of China (nos. 51974225, 51904224, and 51904225).

\section{References}

[1] M. Fall, M. Benzaazoua, and S. Ouellet, "Experimental characterization of the influence of tailings fineness and density on the quality of cemented paste backfill," Minerals Engineering, vol. 18, no. 1, pp. 41-44, 2005.

[2] L. Liu, C. Zhu, C. Qi, B. Zhang, and K.-I. Song, "A microstructural hydration model for cemented paste backfill considering internal sulfate attacks," Construction and Building Materials, vol. 211, pp. 99-108, 2019.

[3] M. Wang, L. Liu, X.-Y. Zhang, L. Chen, S.-Q. Wang, and Y.-H. Jia, "Experimental and numerical investigations of heat transfer and phase change characteristics of cemented paste backfill with PCM," Applied Thermal Engineering, vol. 150, pp. 121-131, 2019.

[4] L. Liu, Z. Fang, C. Qi, B. Zhang, L. Guo, and K. I.-I. L. Song, "Numerical study on the pipe flow characteristics of the cemented paste backfill slurry considering hydration effects," Powder Technology, vol. 343, pp. 454-464, 2019.

[5] L. Liu, P. Yang, C. Qi, B. Zhang, L. Guo, and K.-I. Song, "An experimental study on the early-age hydration kinetics of cemented paste backfill," Construction and Building Materials, vol. 212, pp. 283-294, 2019.

[6] X. Zhao, A. Fourie, and C.-C. Qi, "Mechanics and safety issues in tailing-based backfill: a review," International Journal of Minerals, Metallurgy and Materials, vol. 27, no. 9, pp. 11651178, 2020.

[7] J. G. Liu, X. W. Li, and T. He, "Application status and prospect of backfill mining in Chinese coal mines," Journal of China Coal Society, vol. 45, pp. 141-150, 2020.

[8] X. K. Sun, "Present situation and prospect of green backfill mining in mines," Coal Science and Technology, vol. 48, pp. 48-55, 2020.

[9] B. Hu, P. Liu, F. Cui, and H. Wang, "Review and development status of backfill coal mining technology in China," Coal Science and Technology, vol. 48, pp. 39-47, 2020. 
[10] C. Qi and A. Fourie, "Cemented paste backfill for mineral tailings management: review and future perspectives," Minerals Engineering, vol. 144, Article ID 106025, 2019.

[11] M. Edraki, T. Baumgartl, E. Manlapig, D. Bradshaw, D. M. Franks, and C. J. Moran, "Designing mine tailings for better environmental, social and economic outcomes: a review of alternative approaches," Journal of Cleaner Production, vol. 84, pp. 411-420, 2014.

[12] J. Li and J. Wang, "Comprehensive utilization and environmental risks of coal gangue: a review," Journal of Cleaner Production, vol. 239, Article ID 117946, 2019.

[13] X. Ke, H. Hou, M. Zhou, Y. Wang, and X. Zhou, "Effect of particle gradation on properties of fresh and hardened cemented paste backfill," Construction and Building Materials, vol. 96, pp. 378-382, 2015.

[14] L. Liu, Z. Fang, C. Qi, B. Zhang, L. Guo, and K.-I. Song, "Experimental investigation on the relationship between pore characteristics and unconfined compressive strength of cemented paste backfill," Construction and Building Materials, vol. 179, pp. 254-264, 2018.

[15] C. Qi, X. Tang, X. Dong, Q. Chen, A. Fourie, and E. Liu, "Towards Intelligent Mining for Backfill: a genetic programming-based method for strength forecasting of cemented paste backfill," Minerals Engineering, vol. 133, pp. 69-79, 2019.

[16] Q. Sun, S. Tian, Q. Sun et al., "Preparation and microstructure of fly ash geopolymer paste backfill material," Journal of Cleaner Production, vol. 225, pp. 376-390, 2019.

[17] A. Kesimal, E. Yilmaz, and B. Ercikdi, "Evaluation of paste backfill mixtures consisting of sulphide-rich mill tailings and varying cement contents," Cement and Concrete Research, vol. 34, no. 10, pp. 1817-1822, 2004.

[18] H. Si, H. Bi, X. Li, and C. Yang, "Environmental evaluation for sustainable development of coal mining in Qijiang Western China," International Journal of Coal Geology, vol. 81, pp. 515-521, 2010.

[19] M. Song, S. Wang, and L. Cen, "Comprehensive efficiency evaluation of coal enterprises from production and pollution treatment process," Journal of Cleaner Production, vol. 104, pp. 374-379, 2015.

[20] D. Shang, G. Yin, X. Li et al., "Analysis for green mine (phosphate) performance of China: an evaluation index system," Resources Policy, vol. 46, pp. 71-84, 2015.

[21] H. Li, Y. Liu, and K. Peng, "Characterizing the relationship between road infrastructure and local economy using structural equation modeling," Transport Policy, vol. 61, pp. 17-25, 2018.

[22] C. Jasch, "Environmental management accounting (EMA) as the next step in the evolution of management accounting," Journal of Cleaner Production, vol. 14, no. 14, pp. 1190-1193, 2006.

[23] M. Qian, J. Xu, and J. Wang, "Further on the sustainable mining of coal," Journal of China Coal Society, vol. 43, pp. 1-13, 2018.

[24] X. Xu, X. Xu, Q. Chen, and Y. Che, "The impacts on $\mathrm{CO}_{2}$ emission reduction and haze by coal resource tax reform based on dynamic CGE model," Resources Policy, vol. 58, pp. 268-276, 2018.

[25] L. Liu, J. Xin, B. Zhang et al., "Basic theories and applied exploration of functional backfill in mines," Journal of China Coal Society, vol. 43, pp. 1811-1820, 2018.

[26] O. Žižlavsk, "Net present value approach: method for economic assessment of innovation projects," Procedia-Social and Behavioral Sciences, vol. 156, pp. 506-512, 2014.
[27] Y. Tang and H. Wang, "Development of a novel bentoniteacrylamide superabsorbent hydrogel for extinguishing gangue fire hazard," Powder Technology, vol. 323, pp. 486-494, 2018.

[28] K. K. Agrawal, R. Misra, and G. D. Agrawal, "Improving the thermal performance of ground air heat exchanger system using sand-bentonite (in dry and wet condition) as backfilling material," Energy, vol. 174, pp. 216-235, 2019.

[29] L. Liu, J. Xin, B. Zhang et al., "Exploration of basic theory and application of functional filling in mine," Journal of China Coal Society, vol. 43, pp. 1811-1820, 2018.

[30] L. Li, Y. Lei, and D. Pan, "Economic and environmental evaluation of coal production in China and policy implications," Natural Hazards, vol. 77, no. 2, pp. 1125-1141, 2015.

[31] A. Tariq and E. K. Yanful, "A review of binders used in cemented paste tailings for underground and surface disposal practices," Journal of Environmental Management, vol. 131, pp. 138-149, 2013.

[32] F. Cihangir, B. Ercikdi, A. Kesimal, H. Deveci, and F. Erdemir, "Paste backfill of high-sulphide mill tailings using alkali-activated blast furnace slag: effect of activator nature, concentration and slag properties," Minerals Engineering, vol. 83, pp. 117-127, 2015.

[33] G. B. Stracher and T. P. Taylor, "Coal fires burning out of control around the world: thermodynamic recipe for environmental catastrophe," International Journal of Coal Geology, vol. 59, no. 1-2, pp. 7-17, 2004.

[34] L. Yang, E. Yilmaz, J. Li, H. Liu, and H. Jiang, "Effect of superplasticizer type and dosage on fluidity and strength behavior of cemented tailings backfill with different solid contents," Construction and Building Materials, vol. 187, pp. 290-298, 2018.

[35] E. Yilmaz, M. Benzaazoua, B. Bussiere, and S. Pouliot, "Influence of disposal configurations on hydrogeological behaviour of sulphidic paste tailings: a field experimental study," International Journal of Mineral Processing, vol. 131, pp. 1225, 2017.

[36] J. C. Nunally and I. H. Bernstein, Psychometric Theory, McGraw-Hill, New York, NY, USA, 1994.

[37] R. P. Bagozzi, Y. Yi, and Y. J. Yi, "On the evaluation of structural equation models," Journal of the Academy of Marketing Science, vol. 16, no. 1, pp. 74-94, 1988.

[38] D. Hooper, J. Coughlan, and M. Mullen, "Structural equation modeling: guidelines for determining model fit," Electronic Journal of Business Research Methods, vol. 6, pp. 53-60, 2008.

[39] R. B. Kline, Principles and Practice of Structural Equation Modeling, Guilford Publishing, New York, NY, USA, 3rd edition, 2011. 